\title{
Use of the child health clinic
}

\author{
HILARY HART, MARTIN BAX, AND SUE JENKINS \\ Thomas Coram Research Unit, and Paediatric Unit, St Mary's Hospital Medical School, London
}

SUMMARY Attendance at child health clinics in two areas of London, north Westminster and south Camden, is described. Routine examinations were attended by $97 \%$ of children although such visits accounted for only one-third of attendances. There were more non-routine visits than have been reported in most other studies-about 14 visits in Westminster and 12 in Camden during the first year. Over half the mothers sought advice on a wide variety of medical, developmental, and behavioural problems.

Many remediable conditions can be detected by regular surveillance of young children ${ }^{12}$ but the problem is how best to give such service. The low rate of attendance at many child health clinics suggests that existing services do not always meet the needs of parents and children. There is some evidence that families most in need of help do not use the facilities. ${ }^{3} 4$

Clinic usage is highest in the first year of life, and then decreases after age 2 years. The National Child Development Study found that three-quarters of children $<1$-year old were taken to a clinic but subsequently only half of them continued to attend. ${ }^{5}$ In the Borough of Westminster $77 \%$ of 6-week-old babies had developmental examinations but only $52 \%$ of them had such examinations at 2 years, and $44 \%$ at $4 \frac{1}{2}$ years. ${ }^{6}$ With a few notable exceptions, ${ }^{7}$ clinics run by general practitioners (GPs) do not have higher attendance rates than clinics run by area health authorities. Fifty-nine per cent of children attended for developmental screening at a health centre in Glasgow and $73 \%$ in West Lothian. ${ }^{48}$ This attendance pattern is a legacy of the traditional role of infant welfare centres which originated at the beginning of this century as milk depots and were for a long time primarily concerned with infant feeding. ${ }^{9}$ It is unfortunate that many 2- to 5-yearold children do not receive check-ups for problemssuch as speech and language, and behaviour-that are present in this age group and may predict later difficulties at school.

One important aspect of the child health clinic's work is to help parents with medical, developmental, and behavioural problems for which they do not receive help elsewhere. However, the extent to which clinics provide health care varies considerably throughout the country.
The only certain solution is to seek out families who need help as part of a determined effort to cover the entire population. We describe an attempt to provide an ideal service for preschool children in two areas of London and we identify the features which contribute to the success of such a scheme.

\section{Study populations}

The Thomas Coram Research Unit has been carrying out a longitudinal study of the health, development, and behaviour of preschool children in two areas of London-in north Westminster and south Camden. The study began in 1974 in Camden and in 1975 in Westminster. In each area the study population comprised about 200 families with children under 5 , representing the case load of one health visitor. All the families were initially identified by house-to-house visits and some were discovered who had not been known to the clinic. The survey was repeated at intervals during the study period to check on which families had moved into or out of the area. Newcomers to the area were included in the study but those who moved out were not followed up.

South Camden area. The housing consists mainly of privately- and council-owned flats varying in height from 2 to 12 storeys. Few families have access to a garden although there is a playground. The social class distribution of the families is $51 \%$ in nonmanual and $46 \%$ in manual groups. Two-thirds of the fathers had been born in England, Wales, or Scotland, the remainder had come mainly from Ireland $(10 \%)$, Europe $(10 \%)$, or the Indian subcontinent $(9 \%)$.

There are 9 hospitals within walking distance including a well-known children's hospital. The 
families use about 80 different GPs. The child health clinic is within 10 minutes' walk for mothers in the area and is in a fairly modern, spacious building. The children in the study are generally seen at one session a week which runs from 1330 to 1830 hours. The clinic hours extend into the evening for the convenience of working mothers. About 200 yards from the clinic is the Coram Children's Centre which provides day nursery and nursery school facilities, mother and toddler groups, and a launderette. Children from about age 2 living in the area can attend the children's centre full or part-time and such children receive medical checks at the centre instead of the clinic by the same doctors, so that continuity is maintained. Medical examinations at the centre are conducted with a parent present and the parent is encouraged to consult the doctor about any problem between check-ups either at the clinic or the centre.

North Westminster area. This area has poorer housing than Camden. Most of the accommodation is in multi-occupied houses either privately owned or owned by a housing trust. Many houses are overcrowded, in a poor state of repair, and are causes of complaint. Some of the families have use of a small garden or yard but there are no play areas nearby. Nineteen per cent of the families are in non-manual social class groups and $77 \%$ in manual groups. Only one-third of fathers had been born in England, Wales, or Scotland, the others had come mainly from Ireland $(22 \%)$, the West Indies $(28 \%)$, the Indian sutcontinent $(6 \%)$, or Europe $(8 \%)$.

There is one hospital nearby, and families attend about 80 different GPs.

In the middle of the area is the Dorothy Gardner Centre, incorporating a day nursery, nursery school, mothers' club, and a child health clinic in a new, purpose-built building. As far as we know the integration of child health and preschool educational services in the clinic is unique. Each mother can combine a visit to the clinic with picking up her child from nursery school or attending one of the social functions. There is one morning and one afternoon clinic session - the latter coinciding with a mothers' club session. The clinic is welcoming and friendly, and waiting mothers can make tea or coffee. There is a play area for the children usually with a play helper so that mothers can talk while their children play. Complaints about waiting too long are rare.

\section{Clinical service}

Children are examined routinely at 6 weeks, 6 months, 1 year, 18 months, 2 years, 3 years, and $4 \frac{1}{2}$ years. The examinations are performed by one of three doctors (MB, HH, or SJ) and a medical, behavioural, and developmental history is taken each time a paediatric and developmental examination is carried out. Non-attenders are visited at home by a health visitor and occasionally the mother is offered a home visit by the doctor although most mothers say they prefer to attend the clinic.

At the first attendance parents are told that as well as carrying out routine examinations the clinic offers a clinical service. They are told the times that the clinic is open and are invited to bring any medical, behavioural, or developmental problem to the health visitor or doctor. Each clinic is a walk-in session and parents are encouraged to come as often as they wish.

\section{Attendance for routine examinations}

In both areas $97-100 \%$ of children attended for routine examinations at the various ages specified (Table 1). Of 1900 examinations only 2 were carried out in the child's home. Only one mother persistently refused to bring her child to the clinic or be seen by the doctor at home but the health visitor continued to keep in contact. The $2-3 \%$ of children who missed an examination at one age were seen at the next age unless they had moved from the area.

The children were seen close to the specified age in both Camden and Westminster. For example, the mean age of Camden children at the time of the 1 -year check was 1.002 years with a standard deviation of $5 \frac{1}{2}$ weeks.

In Camden we looked at attendance rates of children who were known to the clinic before the study began and found rates then had been much lower. Seventy per cent of children had had examinations at 6 weeks, $58 \%$ at 1 year, $49 \%$ at 2 years, $47 \%$ at 3 years, and $38 \%$ at $4 \frac{1}{2}$ years.

This comparison was not possible in Westminster as that centre was new.

\section{Clinic visits between routine examinations}

Most mothers used the clinic between routine visits; indeed the majority of visits were not routine

Table 1 Attendances for routine examinations in Camden and Westminster from 1974 or 1975 to mid-1979

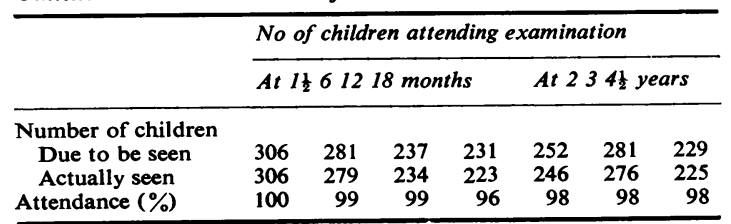


ones and on such occasions the mothers always saw the health visitor and often the doctor. Mothers came very often during the first year, about 14 times in Westminster and 12 (Table 2) in Camden. After the 2nd birthday, by which time immunisations have generally been completed, about three-quarters of children were still brought at least twice a year between routine examinations.

In Camden the number of non-routine visits was lower before the study began. Mothers came an average of 6 times in the first year, once in the second year, and less than once in the third year.

There was no appreciable social class variation in the number of clinic visits during the first year. Neither was there any social class difference between the mothers who were bad attenders and those who were good attenders. Some mothers were extremely good attenders and came more than $\mathbf{3 0}$ times during the first year. Half these mothers had considerable social, housing, or marital problems often associated with depression and anxiety, or with difficulties in coping with their babies. The other mothers appeared to have no particular social disadvantage and seemed to be managing well. Such mothers came to the clinic for social contact and to gain reassurance by discussing their children's progress with the health visitor.

\section{Visits to clinic doctor between routine examination}

In Camden the majority of mothers saw the clinic doctor (as well as the health visitor) during the first year, and about $60 \%$ of them saw him between ages 1-2 and 2-3 years. In Westminster about half the mothers saw the doctor in the first year, and one-third of them saw him between ages 1-2 years and $2-3$ years.

The greater use of the clinic doctor in Camden may reflect the high proportion of middle-class mothers who tend to demand a doctor's opinion in addition to the health visitor's advice. Also, in Camden the doctor saw each child before immunisation whereas this was not the practice in Westminster.

\section{Reasons for clinic visits}

We wanted to know the kind of problems with

Table 2 Clinic attendances between routine developmental examinations during the first 3 years

\begin{tabular}{llc}
\hline & \multicolumn{2}{l}{ Mean number of visits } \\
\cline { 2 - 3 } & Camden & Westminster \\
\hline 1st year & $12 \cdot 5$ & 14.8 \\
2nd year & $2 \cdot 7$ & 6.7 \\
3rd year & 1.9 & 2.4 \\
\hline At all these visits the mother saw the health visitor and often also the \\
doctor.
\end{tabular}

which the mothers felt the clinic might help and to know whether they were satisfied with the service. We looked at this in two ways. Firstly, the mothers were interviewed at home concerning use of the clinic. The interviews were carried out by a set of researchers who did not help to provide the service. As the interviewers were independent of the service we felt they would elicit unbiased opinions. Mothers were asked what they had discussed or sought advice on at clinic visits during the previous 12 months and what had been their opinion of the service. No distinction was made between whether they had talked to the health visitor or doctor as we felt mothers were unlikely to remember whom they had seen.

Secondly, over a 4-month period a record was kept of the reasons why mothers consulted the clinic doctor. In cases of illness the doctor filled in either a diagnosis or the child's presenting symptom. Very often the child's complaint as reported by the mother coincided with the doctor's findings-for example, a cold. In other cases, the child had nonspecific symptoms - such as, a fever or anorexiaand examination had shown otitis media. In such instances the diagnosis rather than the symptom was recorded as we wanted to get a picture of the range of medical conditions seen in the clinic.

\section{Topics discussed in the clinic}

Mothers sought advice most often about their children's illnesses and their eating, sleeping, and toileting; about one-third of mothers remembered discussing such topics in the previous year (Table 3). Developmental problems, speech and hearing, behaviour, housing, preschool provision, and mother's mental state were each discussed by about $15 \%$ of mothers with some variation between the two areas. More Westminster mothers discussed housing problems, reflecting the poor housing conditions. More Westminster mothers said they

Table 3 Topics which 158 mothers remembered discussing at the clinic during previous year

\begin{tabular}{llc}
\hline & \multicolumn{2}{c}{ Mothers who discussed topic } \\
\cline { 2 - 3 } & No & $\%$ \\
\hline Sleeping, eating, toileting & 50 & 32 \\
Illness & 49 & 31 \\
Development & 27 & 17 \\
Speech, hearing & 22 & 14 \\
Behaviour & 20 & 13 \\
Housing & 18 & 11 \\
Preschool provision & 26 & 16 \\
Mother's mental state & 13 & 8 \\
\hline
\end{tabular}

Some mothers discussed more than one topic. 
had discussed psychiatric problems although the social interviewers found that maternal distress in the two areas was similar.

About three-quarters of the mothers said they had been satisfied with advice and help given. The remaining mothers were uncertain whether they had been satisfied, and only $7 \%$ said they were dissatisfied.

Reasons for consulting the clinic doctor. Routine examinations were the reason for consultation only in about one-third of children and even on these occasions mothers had sought advice on a wide variety of problems (Table 4). Over $40 \%$ had sought advice on medical conditions, particularly respiratory or skin disorders. The respiratory illnesses included upper respiratory tract infections, bronchitis, and wheezing. Some parents had already consulted their GPs but were still anxious and came to the clinic for a further examination. Others came to the clinic doctor first and many sought reassurance-for example, about a chesty cough. Some children were referred to the GP for treatment but in most cases examination of the child and discussion with the parent about the natural history of illnesses-such as upper respiratory tract infection-and advice about simple treatment prevented the need for a visit by the GP.

One-third of mothers who had brought their children to the clinic because of illness said they would have liked the clinic doctor to have been able to prescribe medicines although in most cases this did

Table 4 Reasons for consulting the clinic doctor during a 4-month period by mothers of 909 children

\begin{tabular}{lrr}
\hline & \multicolumn{2}{c}{ Children $(n=909)$} \\
\cline { 2 - 3 } & No & $\%$ \\
\hline Routine examination & 310 & 34 \\
New baby check & 31 & 3 \\
Respiratory tract infection & 117 & 13 \\
Skin problem & 95 & 11 \\
Vomiting or diarrhoea & 40 & 4 \\
Feeding & 35 & 4 \\
Teething/colic & 17 & 2 \\
Thrush & 8 & 1 \\
Constipation & 14 & 2 \\
Sight & 12 & 1 \\
Orthopaedic problem & 7 & 1 \\
Surgical problem & 13 & 1 \\
Behaviour & 55 & 6 \\
Development (including speech and hearing) & 26 & 3 \\
Maternal problem (for example, depression, & 12 & 1 \\
$\quad$ anxiety) & 7 & 1 \\
Social problem & 255 & 28 \\
Immunisation & & \\
Miscellaneous (including neonatal jaundice, & & \\
$\quad$ meningitis, hypothyroidism, urinary & & \\
$\quad$ infection, epilepsy, whooping cough, & 30 & 3 \\
injuries) & & \\
\hline
\end{tabular}

Some children were brought for more than one reason. not deter them from consulting the clinic doctor. While preferring to manage most childhood illnesses without drugs we agree with many mothers that the lack of any prescribing facilities at clinics is a shortcoming. Mothers found the clinic a convenient place to bring their sick children and often did so in preference to visiting the GP. Therefore, to have to visit a GP subsequently for treatment is inconvenient, and a waste of their time and that of the doctor. Some clinic sessions were held on the local GP's half-day and acutely ill children had to be referred to the local children's casualty department. In our areas children were brought to the clinic more often than to the GPs in the first 2 years, and if medicines could occasionally be prescribed in consultation with the GP, mothers and children would surely benefit.

Six per cent of children were brought to the clinic doctor because of behavioural problems-most commonly for night waking. The incidence of behavioural problems was higher than this figure suggests and such problems were discussed at each routine visit. ${ }^{10}$

The number of mothers who consulted the doctor about psychiatric problems is not a true indication of the extent of such problems. Some mothers experienced depression or anxiety which affected their perception and handling of their children's difficulties. However, we felt that though a mother might be depressed, a sore throat or fever in the child was often a genuine medical reason for visiting the clinic. Although the mother's mental state might not be discussed on each occasion the fact that she readily visited the clinic with her sick child meant that the doctor was in touch with her and could intervene if appropriate.

It seems clear that mothers regarded the clinic as a source of advice on many health and social welfare problems. We know from looking at the use of other services that few mothers had consulted GPs or hospitals about developmental or behavioural problems. ${ }^{11}$ The clinics therefore were providing a service which parents did not receive elsewhere.

\section{Immunisations}

We looked at the immunisation status of all the children currently in the two experimental areas. Among children aged $<2$ years old in the Westminster area who were old enough to start the course, $97 \%$ had started immunisations. Two children who had not started had recently moved into the area. Eighty-six per cent of children aged between 18 and 24 months and $99 \%$ of those aged between 2 and 5 years had completed their primary courses of diphtheria, tetanus \pm pertussis, and polio vaccine. In Camden $96 \%$ of children aged 3 months to 2 years 
had begun immunisation; 3 children who had not started were only 3 or 4 months' old.

These high immunisation rates correspond with the level of attendance for developmental surveillance and are much higher than in other areas. For example, the overall figure for immunisation in Newham was reported as $70 \%$ in $1976 .{ }^{12}$

Interestingly, there are differences in the proportion of children receiving pertussis immunisation between the two areas. In Westminster two-thirds of children aged $>1$ year received triple vaccine, and one-third diphtheria and tetanus only, compared with Camden where one-third of children $>1$ year had triple vaccine and two-thirds diphtheria and tetanus. Recently more children have been having pertussis vaccine as a result of a rising number of cases of whooping cough.

Among babies aged $<1$ year $90 \%$ in Westminster and $65 \%$ in Camden are receiving triple vaccine. There is evidence therefore that the Camden mothers were either more aware of or had a greater response to the 'scare' about the dangers of pertussis vaccine and are now beginning to want the triple vaccine again.

\section{Implications for services}

The attendance rates given here are considerably higher than reported elsewhere and demonstrate that it is possible to achieve almost complete coverage even in a densely populated inner city area. Not only does this ensure that children receive such care but it has the added benefit of providing comprehensive coverage of preventive health care-such as immunisations.

Unlike France, where payment of family allowance is linked with attendance for regular medical examination, our experience shows that parents can be attracted towards services without financial incentive.

Contrary to the suggestion sometimes put forward that developmental testing can provoke anxieties in parents, we found that the reverse was true. Parents enjoyed talking about their children and watching them take part in developmental tests. Generally the doctor could reassure them about their child's progress. Some parents expressed anxiety about their child's development-for example speech-at the time of examination, but in many cases this was unfounded. Sometimes a parent's expectations of how well her child should be doing was too high and an explanation of normal child development allayed anxiety. In cases in which a problem could be confirmed parents were relieved that it had been recognised and some action taken.

Parents seemed to welcome routine examinations because they provided an opportunity to discuss individual problems. Behavioural problems, typically night-waking, were frequently discussed whereas developmental and behavioural problems are rarely reasons for consulting the GP. It is evident that parents found the doctor's advice valuable by the frequency with which they returned before the next check was due.

The Scandinavian health care system is highly efficient and illustrates the benefits of frequent contact between parents, children, and child health services particularly during the first 2 years of life. In Sweden and Finland, who boast lower infant mortality rates than in the UK, these contacts average between 11 and 13 in the first year. ${ }^{13}$ Our rates of between 13 and 16 clinic visits in the first year compare favourably with Scandinavian figures. The families in our study received home visits by the health visitor also, making the total number of contacts even higher. It has been shown that many cases of cot death have had little contact with a child health clinic or health visitor. ${ }^{14}$ In the Sheffield Child Development Survey mothers of babies who were considered to be at increased risk of cot death were visited at home frequently during the first 5 months. The health visitors were often able to help the mother how to recognise that her baby was ill and to advise her when to seek medical treatment. ${ }^{15}$ In our view if the service were sufficiently attractive it would not be necessary to select high risk groups and all mothers would receive the benefit of frequent contact.

What are the features of a child health service which make it popular with parents? It is difficult to define the reasons for the high attendance at the clinics in this study but from our experience certain issues stand out as being particularly important.

The health visitor. Regular home visiting provides the foundation of community health care. Clinic attendance reflects the level of home visiting as is evident if a health visitor leaves or becomes ill and clinic attendances drop. The health visitor can only maintain a high level of visiting if her case load is of a reasonable size, as in our areas, and she is free of other duties. Our health visitor's case load of 200 families was of a similar size to that for the rest of Camden and Westminster.

Geographical coverage. In areas of high mobility where families visit a large number of GPs and yet some will not have a GP at all, coverage by the community child health team is the most likely way to reach all children. The health visitor attached to a GP without any geographical base is less likely to reach families who move into or out of an area 
without making contact with services. A geographically allocated health visitor becomes well known in her area and will often hear of new arrivals and departures on her rounds. Each area of the country is different and services must be realigned accordingly. In some areas GP attachment of health visitors can be combined with some geographical responsibility, thus offering the advantages of both systems. In city areas with mobile populations served by numerous small general practices geographical attachment is likely to be most effective.

Clinic doctor. Most mothers will come to the clinic for a medical check especially if visited by the health visitor first. But she will return on the next occasion only if she feels the visit was worthwhile. Once a mother is disappointed she may not come again, therefore medical staff must be well qualified and experienced with mothers and children. As far as possible she must be able to see the same doctor at each visit as lack of continuity leads to dissatisfaction and lack of use of health services.

Many clinical medical officers have not had additional paediatric training before joining the community health service and are not equipped to tackle the range of problems (Table 4). In a recent paper Whitmore et al. ${ }^{16}$ stressed the need for a training programme for doctors working in community paediatrics encompassing the areas in which their work requires special expertise-namely (a) physical growth and health, (b) physical and sensory handicaps, (c) intellectual, emotional, and social development, (d) educational medicine, and (e) epidemiology and community medicine. If there were such a programme together with an attractive career structure many high quality doctors could be recruited.

Clinic location and 'links'. Urban clinics should be conveniently situated, within pram-pushing distance and preferably in an area used by mothers. It makes sense to site other services used by families with children under 5-such as nursery schools and day nurseries-near the clinic. The importance of a friendly welcoming atmosphere and an open door policy hardly needs emphasising. The clinic should be part of the social framework of an area. The clinic session enables the mothers to meet and talk, and this very often forms a basis for generating other social and self-help groups.

\section{Conclusion}

The arguments for strengthening the preschool services as recommended by the Court report remain strong. The needs for each area of the country should be considered and met individually.
It should be possible to provide an efficient and comprehensive service using existing resources.

We hope that our experience strikes an optimistic note for those working in the community child health service. We hope the familiar criticism of children's clinics will soon be a thing of the past.

We thank our colleagues in the Thomas Coram Research Unit (in particular the late Professor Jack Tizard, Ian Plewis, and Charlie Owen), the Camden and Islington, and Westminster, Kensington and Chelsea Area Health Authorities for help and cooperation, and our health visitors Carol MacPherson, Susan Rumney, Ann Shanks, and June Thompson.

\section{References}

1 Anonymous. Developmental screening. Lancet 1975; i: 784.

2 Court S D M, chairman. Fit for the future. Report of the Committee on Child Health Services. London: HMSO, 1976.

3 Zinkin P M, Cox C A. Child health clinics and inverse care laws. Evidence from longitudinal study of 1878 pre-school children. $\mathrm{Br}$ Med J 1976; ii: 411-3.

4 Bain D J G. The results of developmental screening in general practice. Health Bull (Edinburgh) 1974; 32: 189-93.

5 Davie R, Butler N, Goldstein H. From birth to seven. London: Longman, 1972.

6 Paterson M T. Developmental screening of pre-school children. Community Med 1972; 128: 423-4.

7 Jenkins G H C, Collins C, Andren S. Developmental surveillance in general practice. $B r \operatorname{Med} J$ 1978; i: 1537-40.

8 Freer C B, Ogunmuyiwa T A. Pre-school developmental screening in a health centre-the problem of nonattendance. $J$ R Coll Gen Pract 1977; 27: 428-30.

9 Craig W S. Child and adolescent life in health and disease. A study in social paediatrics. Edinburgh: Livingstone, 1946: 158.

10 Jenkins S, Bax M, Hart H. Behaviour problems in preschool children. J Child Psychol Psychiatr 1980; 21 : 5-17.

11 Bax M, Hart H. Health needs of pre-school children. Arch Dis Child 1976; 51 : 848-52.

12 Jacob R, Hall C J. Periodic developmental assessment of pre-school children in Newham. Public Health 1976; 90: 179-86.

13 Wynn M, Wynn A. Some developments in child health care in Europe. In: Proceedings of the Eighty-sixth Royal Society of Health Congress, Eastbourne 1979. London: RSH, 1979.

14 McWeeny P M, Emery J L. Unexpected postneonatal deaths (cot deaths) due to recognizable disease. Arch Dis Child 1975; 50: 191-6.

15 Owen B, Portess M. Prospective investigation into cot deaths. Health Visitor $1975 ; 48$ : 379-81.

16 Whitmore K, Bax M, Tyrrell S. Clinical Medical Officers in a Child Health Service. Br Med J 1979; i: 242-5.

Correspondence to Dr Hilary Hart, Thomas Coram Research Unit, University of London Institute of Education, 41 Brunswick Square, London WC1N $1 \mathrm{AZ}$.

Received 28 April 1980 